\title{
In search of a merged identity: the case of multi-campus North-West University, South Africa
}

\author{
F KAMSTEEG*
}

\begin{abstract}
South Africa's post-apartheid governments have taken far-reaching policy measures to transform the system of higher education, do away with its strongly segregated character, and develop an efficient and internationally recognised system that provides equal chances for all ethnic groups. Since 2002 higher education has become the explicit target of a government policy, geared to cultural development and intervention, including the enforcement of a series of mergers between traditionally white and black universities and former technikons (currently universities of technology). This process has caused intense debate at the level of leadership and among policy makers in these institutions, but little is known of how this ideological battle over educational development has affected daily academic practice. This paper gives a first, somewhat tentative discussion on the current effects of the changes in higher education in South Africa, and in particular at one of the institutions affected: the newly merged North-West University (NWU). The article is based on documentary research and three personal visits to the university; in the process a joint research project was initiated between the VU University of Amsterdam (VUUA) and NWU. This paper attempts to shed some early light on how efficiency and social equity goals are met within NWU's institutional merger, beginning from a cultural perspective that focuses on the construction of 'merger narratives'. The paper also gives a voice to critical reactions, narratives of resistance that have emerged from the university shop floor.
\end{abstract}

Keywords: South African tertiary education, North-West University, historically white institutions (HWI, or H Advantaged I) and historically black institutions (HBI, or H Disadvantaged I); mergers; Council on Higher Education (CHE).

Disciplines: Anthropology; Management Studies; Organisation Studies; Higher Education Studies.

\section{Introduction}

In terms of developmental goals, South Africa has long claimed a special position in international politics and policies. As in other cases of politically sanctioned regimes the Western world expended most of its developmental effort on supporting groups, organizations,

* Dr Frans Kamsteeg, an anthropologist with extensive experience in the field of university management and research in organisational studies, is attached to the Faculty of Social Sciences, Department of Culture, Organization \& Management, VU University Amsterdam (VUUA). Email:fh.kamsteeg@fsw.vu.nl. This study is a position paper on a proposed internationally funded project dealing with the merger process at NWU. 
and individuals struggling to liberate themselves from their oppressors. With the demise of the apartheid regime after 1990, support for societal reconstruction in what became known as the 'rainbow nation' meant a new step in development cooperation. The peaceful transition and the relative wealth of the country quickly fostered the assumption that in the post-apartheid period the government would be capable of handling the formidable task of restructuring a new South African society largely unaided, without major external developmental interventions. Ending social inequality - the principal target being the legacy of apartheid - and establishing a politically democratic attitude and practice among a divided population have for the last 14 years been the prime objective of the central government in this transition period. Subsequent elections have put this task in the hands of a single political party, the African National Congress (ANC) that came to power in 1994 with the support of the South African Communist Party (SACP) and the Congress of South African Trade Unions (Cosatu). Since then, the government has focused on the issue of how to expand the economic modernization project started by the previous regime, and simultaneously effect 'societal transformation', redressing the institutionalized and practical inequalities created by successive apartheid governments. This transformation endeavour has even been labelled the ANC National Democratic Revolution (Duvenhage 2007). Education has from the outset been envisioned as an important vehicle in the project. Huge differences in access to education and imbalanced teaching levels are but two of the many obstacles that currently hamper education, preventing it from playing a significant role in the transformation process.

This study is based on documentary source material and information collected at the time of three visits to North-West University (NWU) between February and November 2008. It should be noted that NWU acquired its current form in 2004 after the campuses at Mafikeng, Potchefstroom and Vaal Triangle were merged within the framework of policy guidelines laid down by the government. The study focuses on one particular aspect of the transformation of the South African educational system, namely the state's restructuring of the institutional landscape of Higher Education (HE) by implementing a vast project to merge universities from 2002 onwards. The NWU merger has had a marked impact on the three NWU campuses. Each campus has its own historical background and educational approach, and each, in turn, has responded in a unique manner, impacting on the particular 'urban' and 'rural' surroundings and the ethnic and class complexities of its specific learning environment. Additionally, the way the institutions were centralized, how their values were revised, and how the trajectory of integration was shaped (whether in specific programmes or not) have all affected the quality of academic teaching and research; the administration of the campuses; and the nature of community service.

I shall begin with a section on government policies on the merging of 
universities and then turn to the specific case of the North-West University merger. I will present the NWU case as an ambivalent merging process with significant post-merger integration challenges. I shall then pay brief attention to recent work in similar endeavours, before dealing with post-merger integration processes played out at the shop-floor level at NWU. Both at the institutional-structural level and the life-world level, some narratives of success and failure (Vaara 2002, 2003) are analysed, drawing on different experiences and ways of reasoning. I will also sketch some important themes that emerge from the discussion.

Four years into the merger, the North-West University still appears to be in search of an institutional identity that will unify the three campuses and be shared by the university in its entirety. Although NWU is currently concluding a process of academic alignment, there remain significant differences between the various campuses with regard to teaching, research performance, and institutional culture. These impact on the prospects for a merged identity, which is one of the principal goals to be pursued.

This article is a first contribution to a longitudinal research project that aims at the assessment of the South African merger policy on the basis of an extended, in-depth (multiple) case study of one specific university, NWU. NWU brought together traditionally black disadvantaged and white advantaged universities, with huge differences in institutional cultures and identities. The study aims to trace the complexities arising when this higher educational institution had to undergo rapid change, most evidently because of the fact that three geographically-separate and culturally-distant campuses were brought together under one central institutional management - as a result of government-led policy. With its focus on the examination of culture and identity processes - in the form of sensemaking through narratives - the study claims to add value to dominant managerial perspectives on higher education mergers. With the choice of such a perspective the study will also link up to recent debates on identity and change at higher education institutions.

\section{From the White Paper to the merging reality}

South Africa's higher education history, after a relatively quiet period in the early twentieth century with the foundation of the University of Cape Town (UCT) in 1918, entered an era of turmoil in the early 1990s (Jansen 2003). The newly established government and its successive ministers charged with the Education portfolio considered (higher) education a major vehicle of societal transformation, one that they hoped would go some way towards redressing the legacy of apartheid. The National Commission on Higher Education initiated a programme of change in 1996, and by 1997 this culminated in a policy milestone: the White Paper on Higher Education (1997; see also CHE 2004, 2007; Jansen 2002). During the apartheid period, higher education had developed into a markedly unequal system, 
with disproportionately scattered institutions varying a great deal in size, student enrolment, research capacity, funding, quality of management, etc. The major divide was between historically white institutions (HWI, or HAdvantaged I) and historically black institutions (HBI, or HDisadvantagedI). This was in line with the previous regime's policy of racial separation. Prior to 1994 no government had attempted to bring about a fairer balance; instead the situation was the outcome of deliberate discriminatory policies and a curious laissez-faire policy on tertiary education.

From the outset the ANC government adopted an interventionist approach, directed specifically at educational change. This was the driving force behind the White Paper which gave one single actor, the government, comprehensive power to plan, control and fund the entire sector. The White Paper defined the 'size and shape' of the new system, emphasizing programme-based planning and collaboration; implementation was to be via regional co-ordination and partnerships. Quality assessment, monitored by the Council on Higher Education (CHE), was the third major policy strategy developed in the document and was to provide a sound basis for decisions on structural rearrangements. Mergers did not receive much attention in this document, nor had they done so in the previous National Commission on Higher Education report (Jansen 2003: 3). The issue only came to the fore in the term of the second Minister of Education, Kader Asmal, in 1999. In 2000 he received a report compiled by the CHE team, entitled Towards a New Higher Education Landscape: Meeting the Equity, Quality and Social Development Imperatives of South Africa in the 21st Century. However, this document still did not give a clear indication on how the number of institutions could be reduced by judicious merging. It did however proclaim that 'bedrock' teaching universities should become separated from comprehensive research universities and it promised the end of the binary system. The university sector as a whole, reacted by organising a number of effective protests. This temporally halted far-reaching restructuring (Balintulo 2003: 454ff). Nevertheless, the idea of linking institutional and social redress did not disappear for long. In 2001, The Restructuring of the Higher Education System in South Africa, saw the light of day, presenting a far-reaching programme of mergers as the most appropriate mechanism to bring about transformation, equity, sustainability and productivity (Balintulo 2003: 457). The document also provided a list of merger goals and a fairly concrete number of institutions that had to be merged.

The development in subsequent policy documents demonstrates that the ends of the reorganization of higher education were believed achievable through a deliberately interventionist merging mechanism, i.e. reducing the number of institutions of higher learning. These ends were defined in terms of social development, equity, and quality - in line with the general transformative agenda of the post-apartheid government. Close reading of the 2001 document shows that in addition to its development ends (enhancing access 
and equity for staff and students; and the building of new institutions with cultures and identities transformed beyond the racial and ethnic past), other important economic and efficiency goals were pursued, such as creating economies of scale, and the improvement of the sector's manageability (Jansen 2003: 9). Both the HWIs and the HBIs felt threatened by the proposed top-down operation announced by the ministry. Despite these reservations, once agreed at the Ministry (in December 2002), the policy was implemented. By 2004 the government-mandated merger programme had reduced 36 institutions of higher education to 23: there were to be 11 traditional universities, six universities of technology and six comprehensive universities (See table below). In this operation the former technikons disappeared, either becoming part of one of the comprehensive universities, or transforming into universities of technology. Among the primarily academic 'traditional' universities several of the higher ranked HWU were exempted from merging. The general goals of transformation remained as a set of prerequisites for all institutions.

\section{Scheme of the most important merged institutions since 2004}

\begin{tabular}{|c|c|}
\hline University following merger process & Merger between (Incorporation) \\
\hline University of Cape Town & ----- \\
\hline $\begin{array}{l}\text { University of Fort Hare (Alice, East } \\
\text { London) }\end{array}$ & ---- \\
\hline $\begin{array}{l}\text { University of the Free State } \\
\text { (Bloemfontein) }\end{array}$ & Incorporation of part of Vista University \\
\hline $\begin{array}{l}\text { University of KwaZulu-Natal (Durban, } \\
\text { Pietermaritzburg, Pinetown, Westville) }\end{array}$ & $\begin{array}{l}\text { University of Durban-Westville (Durban) } \\
\text { University of Natal (Pietermaritzburg, Durban) }\end{array}$ \\
\hline $\begin{array}{l}\text { University of Limpopo (Polokwane, Ga- } \\
\text { Rankuwa) }\end{array}$ & $\begin{array}{l}\text { Medical University of South Africa (Ga-Rankuwa), } \\
\text { University of the North (near Polokwane) }\end{array}$ \\
\hline North-West University (Mafikeng, & $\begin{array}{l}\text { University of North-West (Mafikeng, formerly the } \\
\text { University of Bophuthatswana) }\end{array}$ \\
\hline & $\begin{array}{l}\text { Potchefstroom University for Christian Higher } \\
\text { Education }\end{array}$ \\
\hline University of Pretoria & Incorporation of part of Vista University \\
\hline Rhodes University (Grahamstown) & ------ \\
\hline University of Stellenbosch & $\begin{array}{c}------ \\
\end{array}$ \\
\hline $\begin{array}{l}\text { University of the Western Cape (Cape } \\
\text { Town) }\end{array}$ & ------ \\
\hline $\begin{array}{l}\text { University of the Witwatersrand } \\
\text { (Johannesburg) }\end{array}$ & ------- \\
\hline \multicolumn{2}{|l|}{ Comprehensive universities } \\
\hline University of Johannesburg & $\begin{array}{l}\text { Rand Afrikaans University (Johannesburg) } \\
\text { Technikon Witwatersrand } \\
\text { Incorporation of part of Vista University }\end{array}$ \\
\hline
\end{tabular}




\begin{tabular}{|l|l|}
\hline $\begin{array}{l}\text { Nelson Mandela Metropolitan University } \\
\text { (Port Elizabeth) }\end{array}$ & $\begin{array}{l}\text { University of Port Elizabeth } \\
\text { Incorporation of part of Vista University }\end{array}$ \\
\hline $\begin{array}{l}\text { University of South Africa (Pretoria, } \\
\text { Distance Education) }\end{array}$ & $\begin{array}{l}\text { Technikon SA } \\
\text { Incorporation of part of Vista University }\end{array}$ \\
\hline University of Venda (Thohoyandou) & -------- \\
\hline $\begin{array}{l}\text { Walter Sisulu University for Technology } \\
\text { and Science (Buffalo City, Butterworth, } \\
\text { Mthatha, Queenstown) }\end{array}$ & $\begin{array}{l}\text { Border Technikon } \\
\text { Eastern Cape Technikon } \\
\text { University of Transkei }\end{array}$ \\
\hline $\begin{array}{l}\text { University of Zululand (Empangeni) } \\
\text { Universities of Technology University of Technology }\end{array}$ & No merger: incorporation of part of Vista University \\
\hline $\begin{array}{l}\text { Cape Peninsula University of Technology } \\
\text { (Bellville, Cape Town) }\end{array}$ & --------- \\
\hline $\begin{array}{l}\text { Central University of Technology } \\
\text { (Bloemfontein, Welkom) }\end{array}$ & ------ \\
\hline $\begin{array}{l}\text { Durban University of Technology (Durban, } \\
\text { Pietermaritzburg) }\end{array}$ & -------- \\
\hline $\begin{array}{l}\text { Mangosuthu Technikon (Durban) } \\
\text { (Vanderbijlpark) }\end{array}$ & ------- \\
\hline $\begin{array}{l}\text { Tshwane University of Technology (Pretoria) } \\
\text { Vaal ------- }\end{array}$ \\
\hline
\end{tabular}

The fairly generally formulated, transformative character of the educational policy intervention had radical implications. It was designed - and implemented - in a context of political transition, which made it a (probably) unique and a highly hazardous operation. Indeed, tertiary education in post-apartheid South Africa presented itself as a potentially explosive situation. Jansen (2003: 157-159) lists four major transitional conditions, namely:

1. A system deeply marked by racial inequalities (among both staff and students);

2. HBIs (universities and technikons) that suffered severe governance and management crises;

3. declining student enrolment, as a consequence of which the better (white) institutions received the good students and the formerly black institutions the poor students; and

4. a chronic fragmentation and huge imbalances countrywide that reflected the former apartheid government's goals and strategies, the black institutions mainly being located in marginal rural areas.

It was conditions such as these that were targeted for government intervention. Simultaneously, these circumstances were also serious obstacles to success within the confines of tight time schedules. Moreover, the transition process had a twin logic: it was not just the 
legacy of apartheid that was to be overcome, because incorporating South Africa into the globalised world - through education - was equally important. The objective of the Asmal administration that of a single interventionist move, focused on reducing inequality and fostering internationalisation - the latter without having much idea of the implications this might have in terms of substance and organization.

Although understandable as an attempt to correct the effects of many years of political and economic repression, the policy chosen underestimated not only the material, but also the social and cultural effects of the past, where - despite the weakness of the system as a whole - particular groups and institutions had vested interests to defend. It was only logical that the government's explicit steering role in the merging process would produce resistance. It is these macro-conditions that determined much of what has been happening at the micro level, and that to some extent was reproduced at the local level, where university management often played a comparatively strong steering role. These circumstances will be discussed in greater detail below.

\section{A merger case: into the North-West University arena}

In the wake of the world-wide stream of mergers and acquisitions of the last decades there have been a substantial number of publications in the field of organization studies. Merging as an organizational change phenomenon has been studied from many angles: strategically oriented studies, human resource-oriented perspectives and cultural perspectives. The latter approach emerged following the discovery of culture as a metaphor for organizational processes in the $1980 \mathrm{~s}$. As mergers were intended to improve corporate performance, it was only logical that studies on merging often reflected a normative (e.g. 'synergy'), and managerial orientation, which tends to downplay the complexity of the phenomenon (for an overview of the literature, see Vaara 2002; Angwin \& Vaara 2005). An important sub-theme in the merger literature is (the level of postmerger integration, which is often described in terms of 'success' and 'failure', but generally these studies - despite their cultural focus - pay little attention to the stories of the actors involved, or to the specific contexts in which actor perspectives are framed. Even in cultural perspectives, stressing the importance of the variance in norms, values, and beliefs of merging organizations often ignores the complex interplay between culture and the daily social and political manoeuvring of protagonists involved in merging processes. As Angwin \& Vaara (2005) argue in a special issue of Organization Studies, we need empirically better documented, refined, and embedded research that goes beyond the myopia of many of the prevailing cultural perspectives, in which culture is often predicated as either favourable or adverse to merging success. A study of the institutional merger of South Africa's North-West University aims to 
take up this challenge by reconstructing 'merger narratives' that can substantiate the (often ambiguous) imperatives involved in a merger.

The new NWU came into being on 1 January 2004 after a brief but intensive preparatory period under the chairmanship of Theuns Eloff (now the university's vice-chancellor). The process involved a merger of the former Potchefstroom University for Christian Higher Education (PU for CHE), located in Potchefstroom, as well as its Vanderbijlpark campus, some $90 \mathrm{~km}$ further to the east; the former University of the North-West (located in Mafikeng); and the former homeland University of Bophuthatswana, some $200 \mathrm{~km}$ to the west on the Botswana border. This was followed by the incorporation of the staff and students of the Sebokeng campus of Vista University - an apartheid-styled correspondence university.

Officially the university now has three campuses, each with a separate governing body and administration: Potchefstroom, Mafikeng, and the Vaal Triangle (Vanderbijlpark). The three geographically separated campuses are different in size and character. Potchefstroom's staff and student population is predominantly white. The former university had some academic standing and, despite its location in a rural area, attracted students from different parts of the country. Mafikeng is the capital of North West Province, and houses an almost totally black campus that predominantly attracts students from the surrounding rural area; it has a limited academic tradition and in earlier days the university attracted many students from Botswana. The smallest of the three NWU campuses, based in the Vaal Triangle (a highly industrial area), has a mixed staff and student population and has long been a Potchefstroom satellite. In 2004, much to its own surprise, it was assigned independence from Potchefstroom. The latter remains in many ways still NWU's dominant campus, if only because it hosts the hub of administration, known as the Institutional Office.

The research of which this text is the first outcome, was born from a suggestion by the present rector of the Potchefstroom campus to start a collaborative research project between the VU University Amsterdam and NWU on the impact of the merger - a project that falls under the existing memorandum of understanding between the two universities and those of other international multi-university collaborative agreements. It is also in accordance with an internal call (until now unanswered) by the university's vice-chancellor, Theuns Eloff, for a research project to be undertaken on the outcomes of the merger. The reasons for the initial lack of response are as yet unclear, but this present project has taken up the challenge. The feasibility of conducting a longitudinal multi-site ethnographic study of the NWU merger was in general received favourably at all three university campuses as well as at the Institutional Office - by staff members, academic researchers, and students alike. This implies that an assessment can be made of the extent to which the development goals of the institutional merger operation have been reached. To glean results of this wide-ranging nature calls for the (re)construction of the needs, experience and behavioural patterns of all institutional 
actors. In other words the project calls for a collaborative research effort by experienced and junior researchers (from both VUUA and NWU) as well as students from various disciplines and backgrounds. Giving shape to such a collaborative project is in itself complicated; one might venture to say that in a certain sense it is impossible to fully organize and manage the project in a top-down manner.

The design for this study as a multi-researcher effort will be built on the idea of doing research 'with the organization', rather than making a study 'of the organization' from the outside (Neyland 2007). The multi-site ethnographic research design is a complex endeavour, yet turning it into a joint research process including both insiders and outsiders requires further reflection and agreement on role definitions and the scope of the fieldwork. This will be further elaborated following Bartunek and Louis' insider-outsider conceptualization (1992), combined with Moeran's implementation of the observant participation position (Moeran 2006). Such an approach has many advantages (such as broad support of the organization) but it also implies a joint social responsibility. For example, collaboration aimed at improving research capacity, and on a wider scale contributing to NWU's role in social development of the country, is envisioned as a possible additional benefit of the joint project. Yet there are obvious risks. In a situation where the external political context is of crucial importance, any changes in the situation may have a direct impact, while a variety of local interests (within and outside of the university) will also require a great deal of political sensibility on the part of the researchers involved.

\section{A theoretical framework: narrating the merger ${ }^{1}$}

The scope and depth of organization theory requires that the researchers provide justified choices on the approaches to be utilized for the project. Organizational research has predominantly been quantitative in nature, with a strong managerial perspective when it comes to governance questions. Yet organizations are more than structures, they are socially constructed spaces, life worlds, inhabited by real people, who in their meaning-giving activities constantly change organizational reality (see Alvesson 2002, Bate 1997, Watson, 2001). This sensemaking always takes place in an environment where meaning has to be negotiated (Czarniawska 1997). Capturing these sensemaking processes requires a specific approach that is sensitive to their complexities. Retrieving cultural meanings on a merged institution that has drawn together a wide variety of people with

1 Parts of this theoretical section have been taken from an unpublished text prepared during a three-day workshop at Mafikeng, November 2008. This text is the fruit of an intense co-constructed effort on the way towards a fully-fledged research design for the longitudinal project. I wish to thank Gideon Rossouw and Kiran Odhav in particular for their contribution. 
experiences, identities, and expectations that are markedly varied can be fruitfully carried out by carefully reconstructing the 'narratives of change,' drawn from what John van Maanen (1988) calls 'tales from the field'.

Some of these 'tales' on higher education mergers in South Africa have been collated by Janssen (2002, Janssen et al 2000). Although these inspiring studies on the 'micro-politics' of university change (Gibbon, et al 2000) are empirically well informed and highly illuminating. they only do partial justice to the richness of experience, and ambiguous attitudes of those involved in the merger. Moreover, these studies have mainly focused on college mergers; the merging of universities since 2004 is still largely unrecorded. The present study, and its projected continuation, positions itself as following this line of research.

Specific research in organization theory and models on mergers is often bifurcated in a failure-success perspective. The work of Finnish organizational theorist Vaara is useful in pointing to the limitations of "rationalistic explanations for the difficulties in post-acquisition integration" (2003: 859) and shows that little is known on the role of 'irrational' features which can impede organizational integration. The 'success rhetoric' of the rational model leads to a superficial categorization, which does not recognize the role of ambiguity inherent in complex social processes. Acknowledging this complexity creates the opportunity for utilizing different perspectives to develop an understanding of the processes that follow from a merger. While Vaara's work focuses on business organization perspectives, this approach can also be applied in the context of mergers of academic institutions in the tertiary sector.

This approach is located in recognizing the importance of language, and Vaara relies on Cziarnawska (1997) to reflect on the role of narratives as central to an understanding of the social construction of organizational phenomena. The standard approaches in organizational theory can be typified as 'managerialist', but Vaara points out that these do not pay attention to the narratives through which the organizational outcomes of mergers are constructed, and that the 'managerialist' approach does not recognize the role of these narratives in the social construction of outcomes and the decision making processes which role players adopt in post-merger integration. The narrative approach, in short, allows for a perspective that provides for a sequential account, locates intentionality, and sees discursiveness linked to subject positions and identity (Vaara 2002: 215-217). This acknowledges the identity-building processes at work for individuals, including their location within the organizational context.

Scapegoating strategies and conspiracy theories can be linked to particular discourses and one of the conclusions that Vaara's analysis makes, is that both the success and failure versions of narratives can be overly optimistic or pessimistic, depending on their slant. They 
reveal and exemplify "discursive elements through which these phenomena are socially constructed and through which managerial actions are legitimized and naturalized" (2002: 237). This means that actors are able to re-frame the question of failure/success, and that there is not a monolithic, fixed construction placed on their interpretations (ibid.: 239). Vaara also describes "four interrelated tendencies that illuminate why the frequent problem of slow progress during post-acquisition integration occurs", on the basis of "focusing on sensemaking processes surrounding the integration issues" (2003: 1). These tendencies are: inherent ambiguity on integration issues; cultural confusion in social interactions and communication; organizational hypocrisy in integration decision-making; and the politicization of integration issues. Some of these become visible in the following section, which discusses some of the early, as yet tentative merger narratives. The corroboration of their relevance requires more systematic research.

\section{Some initial narrative assertions: on goals, challenges, and distrust}

In its Institutional Plan 2008-2010 NWU claims to have "achieved most of the objectives set out in the Merger and Incorporation guidelines of the Department of Education" (p. 1). The mission focuses on six areas: high quality teaching and research; implementation of expertise (both commercially and community directed); values; sound (financial) management; and transformation. Apart from the goals set for internal purposes, there is a clear awareness of the role that the outside world expects universities to play under the new higher education regime. NWU will

transform continually in terms of positioning, academic profile, unity, equity and redress. In doing this, it will contribute to the transformation of the South African Higher Education system to help meet the country's social, economic, developmental and environmental needs ( $\mathrm{p}$. 6; my italics).

Throughout the document there is an outspoken consciousness of the wider political relevance of complying with these demands ("supplying innovative solutions to challenges faced by the scholarly community, the country, the continent and the world"). Each element of the mission from the document has been translated into an elaborate set of concrete targets.

NWU is projecting itself as a value-driven university. The Potchefstroom campus entrance, for example, conveys this message in neon letters to the personnel and students who enter the campus ("value-driven we make a difference"), although at the other campuses this is not so openly communicated. This focus on values is translated in terms of a single institutional culture for the university which stresses community, tolerance, respect, and human rights. These are to be understood as key values (integrity, commitment, accountability and 
responsibility) to be captured in a Code of Ethics and Conduct that should be debated at all university levels and taken up in individual performance agreements. Two issues are given prominence among the themes defining NWU's specific culture: diversity and human rights. Responsibility for the university's implementation of these issues (plus that of equity) has been assigned to a specific department. Religion is only mentioned in passing, which is remarkable given the fact that historically Potchefstroom is nationally known as a Protestant university. In fact religions (emphatically plural) are only named as possible sources that contribute to university values.

The culture theme does have a prominent place in the values discourse as it is given shape at the university's Institutional Office. In December 2007 the results of a NWU Culture and Climate Study were published (although not widely spread); the implementation of its outcomes ("relevant issues raised by staff") is one of the targets formulated in the Institutional Plan, which also announces additional research (position papers and a student survey) to promote development and to spread the NWU values on diversity. This process is to be closely linked to the branding of NWU's corporate identity, a process that began in 2004. The branding project is organized from the Corporate Communications office, which has spent much effort, time, and money on building the image of a solid, but dynamic organization that meets the demands made by its environment in a creative and distinctive manner. It is in the brand products that an effort is made to show the specific quality of the university as a merger outcome. I give three examples:

- After a long process of discussion and deliberation the corporate logo has recently been finalised. It is to consist of three carefully interwoven "U's", each in the colour of the original university/ campus before the merger (blue, green, and maroon). These colours are used (separately or together) in all corporate publications and on the website.

- An additional symbol is being used to link the merged institution to South African society. Wherever possible publications show a multi-coloured ribbon (the three university colours merging) clearly referring to South Africa as a rainbow nation. Merging diversity at the university is suggested to have broader societal meaning.

- The NWU website shows the same 'diversity in unity' suggested in the mix of colour. Website texts are, moreover, written in the three relevant languages (English, Afrikaans and Setswana). The university's language policy is officially multi-lingual - there is even a programme that provides simultaneous class-room translations, which is heavily promoted nationally and has won several prizes.

These are only a few examples of NWU's corporate branding strategy 
to convey its message of a successful institutional merger. Without going into detail all corporate expressions over the period 2004-2007 have spread this same message (see for example, the Annual Report 2006, 2007; Profile, Pocket Statistics 2007). The list of successes is long and maintains among other things, that:

- student enrolment is increasing;

- the number of undergraduate and honours diplomas continues to rise;

- the racial composition of contact students shows a representative balance;

- female students now outnumber males;

- staff numbers have grown (those of professionals more than nonprofessionals);

- white staff members still outnumber blacks, but the balance is changing (particularly among male staff);

- the university's financial viability is rising;

- external (research) funding is increasing;

- weighted research output continues to increase (to sixth position nationally); and

- the income from industry, science councils and state departments for contract research and development is rising.

To a certain extent this can be interpreted as an example of what Goffman (1959) called front-stage identity-building. Significant figures indicate that progress is indeed being made. This does not, however, mean that feelings of success are shared by all at each of the campuses. At the management and support staff level, both at the Institutional Office and at the campuses, this is generally the case, but among researchers and teachers at the faculties there are mixed feelings. Particularly at the Mafikeng campus there are signs of a distinct critique of the way the new institution is governed and presented to the outside world. This is of course a well-known phenomenon, particularly in mergers where one partner is dominant. Post-merger integration then often shows evidence of feelings of powerlessness and mistrust among the weaker partners (see e.g. Buono and Bowditch 1989). At shop-floor level in the Mafikeng departments, and even among some of the managers, there are critical voices of being 'overpowered' by Potchefstroom change managers and scientists. These critics are reluctant to speak of the merger; they talk instead of 'acquisition' and incorporation in local terms 'Potchefication'. The Mafikeng 'narrative of resistance', ${ }^{2}$ gleaned from respondents, can be paraphrased as follows:

2 Merger narratives at Vaal Triangle campus are notoriously less outspoken. 
'Potch' has always been politically a very conservative university, dominated by a white Protestant elite that has long been supportive to the Apartheid ideology and the regime built on it. They see Mafikeng as a place for black rural students, and it serves them well to have a substantial number of them. The new NWU institution is a kind of apartheid in disguise, but presented as a successful attempt to transform the university landscape (and Potchefstroom) away from its apartheid past. The Institutional Office, still situated on the Potchefstroom campus, is developing and implementing plans like a bulldozer, without listening to the periphery. Research is concentrated at Potch - the other campuses are for teaching only. The dominant language at Potchefstroom is still Afrikaans, which excludes most black students from the better programmes. There is hardly any teacher mobility between the campuses either. The official language policy does not recognize the real language problems most black students have. Procedural streamlining has been done according to the Potch model. The academic programme alignment is now going to follow the same path. Income-generating projects also largely benefit the Potch campus, which has, moreover, the better research and teaching facilities. Although the university is presented as a single institution, which represents the new equity and redress ideology designed by the government, at best it is a federal organization, with one centre dominating the periphery. We have been the product of apartheid, and now we are used again as a loincloth of post-apartheid transformation.

It is clear that imagery plays a dominant role in this strong narrative 'from the margins', as much as it does in the narratives of success and progress expressed by NWU's institutional management. In fact, all shades between black and white are to be found in the images they contain. These narratives are weapons from what could be called an arena where different players - with different power positions struggle over meaning. All figures and events, their interpretation, and subsequent presentation then become contested. The current general management, and the vice-chancellor, Theuns Eloff in particular, do acknowledge that the merger is still fragile in term of its culture and identity. There are shortcomings Eloff sees as challenges that have to been taken seriously while continuing along the chosen path. EISH!, (2008) a student quarterly, has a telling interview with the vice-chancellor, in which he summarises the present situation and the priorities for the future as follows (emphasis is mine), thus providing a totally different narrative:

NWU has done very well as a merged university during the last few years... Recent achievements include... an improved throughput rate, strongly improved research outputs, financial success, and general student stability on all three campuses. We have maintained the balance between unity and diversity, made good progress with employment equity, and have made a constructive start with academic alignment. There is a special focus on quality and unity. The 2008 quality drive will be directed ... at the ... HEQC audit and the unity drive ... at alignment, synergy 
and building a sense of unity.

Unity ... falls into three aspects ... the academic alignment process must gather even stronger momentum, and I implore especially our academics to throw themselves into this with passion; synergy ... the NWU must be more than the sum of its parts; building a sense of unity is difficult and costly, but also unavoidable and desirable. The success of the intercampus social days ... bears testimony to this. The balance between unity and diversity should be carefully managed. ${ }^{3}$ However, social meetings, including sports events, are only the first - and probably the easiest - means to contribute to better integration. Attempts at academic encounter and exchange that might lead to integration, are most probably more difficult to become effective (EISH! 2008).

A similar urge for unity was expressed by Prof. Annette Combrink, the campus rector at Potchefstroom, on the occasion of the official opening of the academic year 2008. She mentioned NWU's values, new governance structure and the transformative efforts designed to facilitate the move towards institutional cohesion. Comparable messages were conveyed by the respective campus rectors in their opening ceremony speeches at Mafikeng and Vaal Triangle (Combrink 2008).

To sum up: what has been achieved at NWU in the first four years of its existence as a merged institution? The institution has been restyled, the multi-campus structure being the most prominent outcome, creating a single operational management centre and separate campus administrations. NWU has even been awarded the prize for the best governed university in SA. The university - at least the Potchefstroom campus - has become pro-active as a business partner that sells knowledge. And there are more organizational improvements that could be mentioned. As far as the societal goals are concerned less progress appears to have been made, despite the fact that in a comparative South African perspective, NWU has probably made more progress than other merged universities. Although the merger has created a more representative and diverse student population when the institution as a whole is taken into consideration, overall ethnic representation among students and staff (administrative and academic) is still highly uneven between the campuses. Academic programmes are currently being aligned, a process that does not always run smoothly between campuses and faculties; this adds to existing critical narratives, with respondents indicating that NWU's reality is still a place of contested meaningmaking. Institutional identity discourses constructed by its administrators are regularly questioned at shop-floor level; evidently,

3 The back cover of the magazine has some pictures of the social event Eloff mentions, showing a relaxed setting in which employees from the various campuses, are taking part in various activities together, wearing clothes with the respective campus colours. 
perspectives diverge most frequently between employees at the Potchefstroom and Mafikeng campuses, while the Vaal Triangle campus generally takes a less outspoken middle position.

\section{Some tentative interpretations and concluding remarks}

In present-day South Africa social and economic development is the outcome of a neo-liberal free market policy combined with and/or restricted by certain government measures. These measures are basically driven by the desire to establish equity and redress the inequalities of the apartheid era. Black empowerment and the corresponding affirmative action are the main pillars of this policy of redress. The restructuring of the system of (higher) education is one of the government's interventions made to enhance the speed of the developmental process. Increasing the level of education among (black) South Africans is viewed as a pivotal means of providing society, and the private sector in particular, with educated people to achieve the projected economic growth. To reach this goal, the government has enforced the policy of merging institutions of higher education. The ideology behind this project is to target social redress (establishing equity of access, and ethnically/racially representative institutions). Another goal is to create better integrated, wellorganized and financially sound institutions of higher education. The present South African higher education field can thus be seen as a developmental 'laboratory' in which the general policy of combined neo-liberalism and state intervention is played out. Yet, although the general path of the restructuring of the sector has been government imposed (e.g. the list of merged institutions is a political decision, not the outcome of a free discussion), the process and progress in each merged institution has not yet been strictly monitored. Assessment of the outcomes of the merger process is a recent step. and indeed there are major differences to be observed, not only in terms of the route each institution chose to follow, but also in the extent to which institutions have managed to meet their targets - those set by the government and those they themselves have defined.

NWU management is conveying a fairly self-confident image of success. The governance structure is in place; administrative procedures (including tuition fees and staff salaries) have been 'aligned', and financial indicators are positive. Integrating culture and identity, although on the agenda from the beginning, is a goal that still has a long way to go. As an anonymous informant, one of the architects of the merger, once told me: 'It is received wisdom that culture follows structure'.

Yet the critique described above does not only come from the departments of the 'outer' campuses at Vaal Triangle and Mafikeng. On a recent visit to the university, the Minister of Education, Naledi Pandor, indicated that she was impressed by the statistics provided, but expressed doubts about whether NWU was really a merged 
institution, given the three distanced campuses. She thus not only echoed a concern experienced by many at the campuses of Vaal Triangle and more particularly at Mafikeng - it would seem that other merged institutions in the country have similar issues that need to be addressed. The minister's comments sounded a warning, and demonstrated that she felt that NWU's merger structure was a 'federal' structure, which might not be appropriate in the ANC's 'democratic revolution' and its demands of redress, despite the official picture emanating from the available statistics.

Although the minister only made these remarks in passing and amidst other more eulogising comments (e.g. on NWU's entrepreneurial spirit) ${ }^{4}$ a recent analysis of institutional culture(s) in South Africa by Higgins (2007), published by the Council on Higher Education, suggests that they might not be without wider significance. Higgins argues that one of the major obstacles for redressing (ethnic/racial) inequality in higher education institutions is the dominant culture of whiteness, understood as the dominance of Anglo-Saxon values and attitudes. Taking on Bourdieu's notion of cultural capital he further refines the 'whiteness critique' by broadening this category (following Steyn \& van Zyl 2001) to include

\begin{abstract}
Euro-American worldview, English-speaking as mother-tongue, maleness, heterosexuality, able-bodiedness, (upper) middle-classness, South African nationality, urban background, etc., (Higgins 2007: 110).
\end{abstract}

The dominance of this complex of values and practices (or in short, cultural capital), he continues, is responsible for the experience of alienation and anomie of the subordinated, or, in South African terms, under-privileged black people. In a situation with three separate campuses, of which the dominant campus clearly represents the culture of whiteness (in the sense of cultural capital described by Higgins), it is doubtful, or at least questionable, whether the social ends of the government's 'merger project' can really be achieved in the immediate future. Critical voices from academics at the various NWU campuses reflect a persistent mistrust of the Potchefstroom administrators; this has tended to dominate institutional reorganisation. This also points to another critique on the present university culture, an issue that Higgins describes as the 'dominance of new managerialism' (ibid.: 112).

The South African Higher Education project to merge institutions is a political project par excellence. It is an expression of the ANC government's perspective on national development, their 'national democratic revolution' ideology. At a general level the government has opted to support neo-liberal economic policies, while in the

4 It would be an interesting sub-theme to this research project to study whether this entrepreneurial spirit can be linked (in the Weberian sense) to the markedly Protestant background of the Potchefstroom campus. 
domain of government institutions preferential treatment (black empowerment) is chosen as the major strategy of the social transformation agenda. In education - generally considered a powerful vehicle of development - we see a similar dual strategy of a liberal market policy on the one hand and top-down managerial intervention and control on the other. In the higher education sector that is most clearly visible in the merger operation. Institutions are merged for efficiency reasons and obliged to display an entrepreneurial spirit to augment their financial resources. Apart from 'solving' some of the economic problems of the higher education sector, the merged institutions are designed as vehicles to tackle the equity problem in its broadest sense. The NWU merger is an example of how this governance model unfolds: a mix of market logic and moral politics, based on the genuine belief that both will, in the end, contribute to improving the standard of living and quality of life for the majority of previously disadvantaged South Africans. Despite the strong moral drive of government, religion does not play a public role in underpinning political decision-making and ensuing government policy measures. As such, it might perhaps be considered a case of secular political theology. NWU has conformed to this ideology by adopting an explicit defence of value pluriformity and diversity. Despite the fact that the vast majority of staff on all three campuses have a Christian orientation, and manifestations of this regularly occur, explicit references to the university's Christian character have disappeared from university policy documents.

Attempts to bring about change in culture and identity processes must take into account that these attempts are never uncontested, certainly not in merging situations. Further study is required to identify the various arenas of conflict and cooperation. This will hopefully ensure development and future sustainability of an institutional identity that will be conducive to real communication, mutual understanding, exchange of ideas and cooperation. The leading question in such research on NWU post-merger processes of organizational integration and identity-building, might well be how these are being reflected in, culturally constructed, narrative discourses, because these can be retrieved from experiences and opinion of the relevant university constituencies: students, staff, and management. To enable scientific as well as political dialogue on these issues, it would be highly productive to create joint interpretative spaces (Rynes, Bartunek, Daft 2001) in which researchers, lecturers, managers and students from various disciplines can share, in an integrated manner, their experiences and opinions.

\section{References}

Alvesson, Mats. 2002. Understanding Organizational Culture. Thousand Oaks: Sage.

Angwin, Duncan and Eero Vaara. 2005. Introduction to the special 
issue. 'Connectivity in merging organizations: beyond traditional cultural perspectives'. Organization Studies 26 (10): 1445-1453.

Balintulo, Marcus. 2003. The role of the state in the transformation of South African higher education, 1994-2002: equity and redress revisited. In Paul Tiyambe Zeleza and Adebayo Olukoshi, African Universities in the Twenty-first Century, vol. II Knowledge and Society, Dakar: CODESRIA, pp. 441-458.

Bartunek, Jean M. and Meryl Reis Luis. 1992. 'Insider/outsider research teams: collaboration across diverse perspectives'. Journal of Management Inquiry, 1/2: 101-110.

Rynes, S., Bartunek, J., \& Daft, R. 2001. 'Across the great divide: knowledge creation and transfer between practitioners and academics'. Academy of Management Journal 44 (2): 340-355.

Bate, S.P. 1997. 'Whatever happened to organizational anthropology? A review of the field of organizational ethnography and anthropological studies'. Human Relations 50 (9): 1147-71.

Buono, A.F. and Bowditch, J.L. 1989. The Human Side of Mergers and Acquisitions: Managing Collisions between People, Culture and Organisations. San Francisco: Jossey Bass.

Combrinck, A. 2008. Campus rector Potchefstroom: Opening address at the start of the new academic year.

Council on Higher Education. 2007. Review of Higher Education in South Africa. Pretoria: The Council on Higher Education.

Czarniawska, Barbara. 1997. Narrating the Organization. Chicago: University of Chicago Press.

Department of Education. 1997. A Programme for the Transformation of Higher Education. Education White Paper 3. Pretoria: Government Printer.

EISH! 2008. '2008 - the year of quality and unity'. EISH!, the Quarterly Staff Newsletter for the People of NWU, 2 (1).

Gibbon, P., A. Habib, J. Jansen and A. Parekh. 2000. 'Accounting for change: the micropolitics of university restructuring'. South African Journal of Higher Education 14 (3): 15-26.

Higgins, John. 2007. 'Institutional culture as keyword'. In Council on Higher Education, Review of Higher Education in South Africa. Pretoria: the Council on Higher Education, pp. 97-123.

Jansen, Jonathan, et al. 2007. 'Tracing and explaining change in higher education: the South African case. In Council on Higher Education. 2007. Review of Higher Education in South Africa. Pretoria: the Council on Higher Education, pp. 157188.

Jansen, Jonathan (ed.). 2002. Mergers in Higher Education. Lessons 
Learned in Transitional Contexts. Pretoria: University of South Africa.1

Jansen, Jonathan. 2003. 'Mergers in South African higher education: theorizing change in transitional contexts'. Politikon, South African Journal of Political Studies 30 (1): 27-50.

Kishun, Roshen. 2007. The internationalization of higher education in South Africa: progress and challenges'. Journal of Studies in International Education 11 (3): 455-469.

Ministry of Education. 2002. Transformation and Restructuring: A New Institutional Landscape for Higher Education. Pretoria: Government Printer.

Moeran, Brian. 2006. Ethnography at Work. Oxford: Berg.

National Working Group. 2001. The Restructuring of the Higher Education System in South Africa. Pretoria: Government Printer.

Neyland, Daniel. 2008. Organizational Ethnography. London: Sage.

North-West University. 2007. Institutional Plan 2008-2010. Potchefstroom: NWU.

North-West University. 2008. Annual Report 2006. Potchefstroom: NWU.

North-West University. 2008. Annual Report 2007. Potchefstroom: NWU.

North-West University. 2008. 2007 Profile. Potchefstroom: NWU.

North-West University. 2008. Pocket Statistics 2007. Potchefstroom: NWU.

Steyn, M. \& van Zyl, M. 2001. 'Like the statue at Jammie stairs: some student perceptions and experiences of institutional culture at the University of Cape Town in 1999'. Research Report, Institute for Intercultural and Diversity Studies, UCT.

Vaara, Eero. 2002. 'On the discursive construction of success and failure in narratives of post-merger integration'. Organization Studies 23 (2): 211-248.

Vaara, Eero. 2003. 'Post-acquisition integration as sensemaking: glimpses of ambiguity, confusion, hypocrisy, and politicization'. Journal of Management Studies 40 (4): 859-894.

Van Maanen, John. 1988. Tales of the Field. On Writing Ethnography. Chicago: The University of Chicago Press.

Watson, Tony J. 2001 [1994]. In Search of Management. Culture, Chaos $\&$ Control in Managerial Work. London.: International Thomson Business Press.

What Works Strategic. 2007. NWU Culture and Climate Study 2007. Analysis of Results. Interpretive Report. Allen's Nek: What Works 
Strategic.

Yu, Jisu, Rhonda M. Engleman and Andrew H. Van de Ven. 2005. The integration journey: an attention-based view of the merger and acquisition integration process'. Organization Studies 26 (10): 1501-1528. 